\title{
Duplex Stainless Steel Welds and their Susceptibility to Intergranular Corrosion
}

\author{
B. Gideon ${ }^{1 *}$, L. Ward ${ }^{2}$ and G. Biddle \\ ${ }^{1}$ ARV Offshore, 199/62 LandCo Building, Vipavadee-Rangsit Road Samsaen-Nai, Phayathai, \\ Bangkok 10400, Thailand. \\ ${ }^{2}$ School of Civil and Chemical Engineering, RMIT University, GPO Box 2476V, Melbourne, Vic. \\ 3001, Australia \\ ${ }^{3}$ Surface Materials Analysis Research \& Training Group, Department of Applied Physics RMIT \\ University, GPO Box 2476V, Melbourne, Vic. 3001, Australia \\ *Corresponding Author: barry@arv-offshore.com
}

\begin{abstract}
Duplex stainless steels (DSS) as alternatives to conventional austenitic stainless steels for the construction of pipelines is becoming more wide-spread, particularly for sour service applications where corrosion resistance / stress corrosion cracking resistance is required in aggressive chloride / sulphide environments. While these steels show many superior characteristics, limitations are associated with the welding of these steels, particularly controlling the weld structure and properties and understanding how the weld metallurgy may influence the susceptibility to intergranular corrosion $(I G C)$.

The focus of this paper is to report on the findings from a detailed study of the various weld sections within a DSS pipeline, as a function of heat input and type of weld, in terms of the metallurgical structure, composition and mechanical properties and to assess the susceptibility to IGC. Welding was performed using the manual Gas Tungsten Arc Welding $(G T A W)$ technique at both high and low heat input conditions. Two different join configurations (double bevel single $V$ bevel and double bevel single $U$ joint configuration) were adopted. Structural analysis consisted of (i) optical microscopy of welded specimens; (ii) ferrite content determination; (iii) Vickers hardness measurements; (iv) Charpy impact studies and (v) transverse tensile testing. Two test methods namely a modified ASTM A262 and a modified Double Loop Electrochemical Potentiokinetic Reactivation (DL-ERP) test was used to determine susceptibility to IGC. The electrolyte solution used was $0.5 \mathrm{M} \mathrm{H}_{2} \mathrm{SO}_{4}+0.001 \mathrm{M}$ TA (thioacetamide). The test was conducted at $60^{\circ} \mathrm{C}$. The potential was scanned from -500 $\mathrm{mV}$ (SCE) to +200 $\mathrm{mV}$ (SCE) and back to $-500 \mathrm{mV}(\mathrm{SCE})$ at a rate of $1.67 \mathrm{mV} / \mathrm{s}$. The ratio of the reactivation charge to the passivation charge was calculated. From the results obtained it can be shown that the fill region was most susceptible to IGC for all weld conditions.
\end{abstract}




\section{INTRODUCTION}

DSS with a microstructure comprising of proportionate amount of ferrite and austenite, have both the properties of austenitic and ferritic stainless steels such as high tensile strength, good toughness at low temperatures and excellent resistance to stress corrosion cracking (1). They are used increasingly as an alternative to austenitic stainless steels, especially in chloride or sulphide environments, e.g., in the oil, gas and petrochemical industries, as such is a prime candidate for sour service application (2). In the welding of DSS, it is essential to maintain a ferrite-austenite ratio close to 50:50. This phase balance, may however, be upset due to rapid cooling involved in most weld thermal cycles resulting in weld metal ferrite contents in excess of 50\%. In order to restore the phase balance, weld filler materials are usually overalloyed with $\mathrm{Ni}$ than in the base material (3). The resultant phase ratio is dependent on the energy input during welding, as this determines the cooling rate and the extent of the phase transformation which is diffusion based. If high heat inputs are used, coarser grains are produced in the weld region, wide heat-affected zones and possibly, precipitation of brittle intermetallic phases may develop $(4,5)$. However, due to the resultant slow cooling rates, the transformation may yields a more favorable phase balance. It is thus desirable to control welding conditions such that cooling is slow enough for adequate formation of austenite, but fast enough to prevent the formation of precipitation (6).

It has been reported $(7,8,9)$ that various intermetallic phases $(\chi, \sigma$ and $\mathrm{R})$ can be present in the weld metal under different aging conditions. These phases are predominantly associated with slow cooling rates through specific temperature regions from $600^{\circ} \mathrm{C}$ to $1000^{\circ} \mathrm{C}(9)^{\circ}$ It has been shown that the effect of intermetallic phases on the majority of the weld metal properties may only be significant at approximately $2 \%$ volume (10). Secondary austenite ( $\left.\gamma^{\prime}\right)$ has also been identified in the reheated weld beads of DSS. The corrosion resistances in these welds are reduced due to the lower $\mathrm{Mo}, \mathrm{Cr}$, and $\mathrm{N}$ contents in primary austenite, and as a result, welds containing $\gamma^{\prime}$ have poorer corrosion resistance (11). One way to limit the formation of $\gamma^{\prime}$ in the weld region is to reduce the heat input in the successive passes. This will reduce the reheating and cooling cyclic effect on the structure of the root pass, which will also be in contact with corrosive liquids medium in linepipe. Nilsson et al. (11) determined that the as welded microstructure was almost devoid of intermetallic phases, but a small amounts of $\gamma^{\prime}$ was present. This observation was based on multipass welds with heat inputs of either $0.8 \mathrm{~kJ}$ or $1.4 \mathrm{~kJ}$ and interpass temperatures not exceeding $100^{\circ} \mathrm{C}$.

Heat input and interpass temperature are the two main welding parameters often cited as influencing the cooling rate. It has been determined that increasing the heat input increases the width of the HAZ (12), while the use of high heat input increases the corrosion resistance has also been reported (13). A simulated multipass welds was developed to show that the toughness of the HAZ exhibited a maximum when the interpass temperature was maintained below $100^{\circ} \mathrm{C}$. In addition, it was established that the toughness of the HAZ increased with an 
increase in cooling rate (14). It has also been demonstrated that as the interpass temperature increases, the cooling rate decreases (15).

Numerous papers have been published on the microstructures of duplex stainless steel weld metal and HAZs, but detailed studies of the as welded structures and their susceptibility to sensitization are limited.

The aim of this study is to conduct a detailed analysis of the various weld sections within a DSS pipeline, as a function of heat input and type of weld, in terms of the metallurgical structure, composition and mechanical properties and to assess the susceptibility to IGC.

\section{EXPERIMENTAL PROCEDURES}

\subsection{Welding Conditions}

The parent material chosen for the investigation was a $10 \mathrm{~mm}$ wall thickness, $250 \mathrm{~mm}$ diameter DSS linepipe corresponding to UNS 31803. The filler material used was the conventional ER2209 AWS A5.9-93 classification. Full details of the chemical composition of both the parent material and filler material are listed in Table 1, confirming that the primary solidification mode was ferrite.

Table 1. Chemical composition of pipe and filler material.

\begin{tabular}{lllllllllllllll} 
& & $\mathrm{C}$ & $\mathrm{Mn}$ & $\mathrm{P}$ & $\mathrm{S}$ & $\mathrm{Si}$ & $\mathrm{Ni}$ & $\mathrm{Cr}$ & $\mathrm{Mo}$ & $\mathrm{N}$ & $\mathrm{Cu}$ & $\mathrm{Pren}$ & $\mathrm{Cr}_{\mathrm{eq}}$ & $\mathrm{Ni}_{\mathrm{eq}}$ \\
\cline { 2 - 12 } Pipe & Min & - & - & - & - & - & 5.00 & 21.50 & 3.00 & 0.15 & - & 35 & - & - \\
& $\mathrm{Max}$ & 0.030 & 2.0 & 0.025 & 0.015 & 1.0 & 6.50 & 23.00 & 5.50 & 0.20 & 0.16 & - & 32.04 & 10.78 \\
Filler & $\mathrm{Max}$ & 0.016 & 1.69 & - & - & 0.42 & 8.60 & 23.07 & 3.20 & 0.160 & 0.16 & $\geq 35$ & 28.09 & 11.90 \\
Material & & & & & & & & & & & & & &
\end{tabular}

Note; $\mathrm{Cr}_{\mathrm{eq}}=\mathrm{Cr}+1.37 \mathrm{Mo}+1.5 \mathrm{Si}+2 \mathrm{Nb}+3 \mathrm{Ti}$ and $\mathrm{Ni}_{\mathrm{eg}}=\mathrm{Ni}+22 \mathrm{C}+0.31 \mathrm{Mn}+14.2 \mathrm{~N}+\mathrm{Cu}$

Welding was performed using the manual Gas Tungsten Arc Welding (GTAW) technique. Two different join configurations were adopted, namely double bevel single $\mathrm{V}$ bevel and double bevel single $\mathrm{U}$ joint configuration. Details are given in Table 2.

Upon completion of welding, all test conditions were visually inspected for surface defects both internally and externally. Liquid dye penetrent tests were performed 4 hours after completion of welding, and radiography (X-ray) was performed 24 hours later to determine the integrity of the girth welds. 
Table 2 Weld Conditions

\begin{tabular}{|c|c|c|c|}
\hline Weld Condition & $\begin{array}{l}\text { Weld } \\
\text { Pass } \\
\end{array}$ & Travel Speed & Heat Input \\
\hline \multirow{4}{*}{ Condition 1} & & $\mathbf{m m} / \mathbf{m i n}$ & $\mathrm{J} / \mathrm{min}$ \\
\hline & 1 (weld root) & 51.00 & 1474.71 \\
\hline & 2 (weld fill) & 123.00 & 883.12 \\
\hline & 3 (weld fill) & 66.00 & 1745.45 \\
\hline \multirow{3}{*}{ V groove } & 4 (weld fill) & 64.00 & 1788.00 \\
\hline & 5 (weld cap) & 64.00 & 1685.63 \\
\hline & & Average & 1515.38 \\
\hline \multirow{2}{*}{ Condition 2} & 1 (weld root) & 45.00 & 1591.20 \\
\hline & 2 (weld fill) & 105.00 & 1440.46 \\
\hline \multirow{3}{*}{ V groove } & 3 (weld fill) & 79.00 & 2756.05 \\
\hline & 4 (weld cap) & 94.00 & 2216.17 \\
\hline & & Average & 2000.97 \\
\hline \multirow{3}{*}{ Condition 3} & 1 (weld root) & 110.00 & 419.78 \\
\hline & 2 (weld fill) & 62.00 & 757.55 \\
\hline & 3 (weld fill) & 38.00 & 1733.05 \\
\hline \multirow{3}{*}{$\mathrm{U}$ groove } & 4 (weld fill) & 40.00 & 2194.80 \\
\hline & 5 (weld cap) & 43.00 & 2041.67 \\
\hline & & Average & 1429.37 \\
\hline \multirow[b]{2}{*}{ Condition 4} & 1 (weld root) & 115.00 & 420.31 \\
\hline & 2 (weld fill) & 66.00 & 942.55 \\
\hline \multirow{3}{*}{ U groove } & 3 (weld fill) & 73.00 & 2219.18 \\
\hline & 4 (weld cap) & 57.00 & 2135.37 \\
\hline & & Average & 1429.35 \\
\hline
\end{tabular}

\subsection{Mechanical Testing}

Ferrite contents of the four weld conditions were measured using the Magna-Gauge, Fischer ferritescope and as a comparison, determined metallographically by point count method (16).

Vickers hardness measurements were made with a $10 \mathrm{~kg}$ load in the parent material, HAZ, weld cap, weld fill and weld root regions. Transverse tensile test specimens were used to determine the tensile values whilst the more restrictive transverse side bend specimens was used. Charpy impact tests were performed to assess the notch toughness of samples extracted from the weldments as described in ASTM A 370 (17).

\subsection{Intergranular Corrosion tests (IGC)}

Two test methods namely a modified ASTM A262 (25) and a modified Double Loop Electrochemical Potentiokinetic Reactivation (DL-ERP) test was employed to determine susceptibility to IGC. 
Modified ASTM A262 Standard Practices E-copper-copper sulfate sulfuric acid test for detecting susceptibility to intergranular attack was used. The specimen was covered with copper shot and grindings and immersed in a solution of $16 \mathrm{wt} \%$ sulfuric acid with $6 \mathrm{wt} \%$ copper sulfate. The solution was then heated to its boiling point and maintained at this temperature for 48 hours. On removal from solution, the specimen was bent through $180^{\circ}$ over a rod with a diameter equivalent to twice the thickness of the specimen instead of four times the thickness to ensure if cracks appeared they would be apparent by the more restrictive bending radius. The bent surface of the specimen was then examined for cracks at low magnifications in the range X5 to X20.

A modified double loop test was used as conducted by Schultz et al (19-21) as described in Fig.1. The solution used was $0.5 \mathrm{M} \mathrm{H} 2 \mathrm{SO} 4+0.001 \mathrm{M}$ TA (thioacetamide). TA is added to reduce the extent of ferrite dissolution. The test was conducted at $60{ }^{\circ} \mathrm{C}$. The polarization scan was started 5 minutes after immersion of the specimen. The potential was scanned from $-500 \mathrm{mV}$ (SCE) to $+200 \mathrm{mV}$ (SCE) and back to $-500 \mathrm{mV}$ (SCE) at a rate of $1.67 \mathrm{mV} / \mathrm{s}$. The ratio of the reactivation charge to the passivation charge was calculated and is shown in the results and discussion section. Schultze et al also evaluated the single loop test described in ASTM G108 for DSS on the basis that the extent of ferrite dissolution would be less in a single loop test than in a double loop test. It was also suggested that the EPR method could be applied to DSS welds but was not conducted.

\begin{tabular}{|l|l|l|}
\hline & $\begin{array}{l}\text { Non } \\
\text { Sensitized } \\
\text { Weld } \\
\text { Material }\end{array}$ & $\begin{array}{l}\text { Sensitized } \\
\text { Weld } \\
\text { Material }\end{array}$ \\
\hline $\begin{array}{l}\text { Ir/Ia } \\
(\%)\end{array}$ & $<1$ & $\geq 1$ \\
\hline $\begin{array}{l}\text { Qr/Qa } \\
(\%)\end{array}$ & $<1$ & $\geq 1$ \\
\hline
\end{tabular}

Sensitization criteria based on $(28-33,38)$

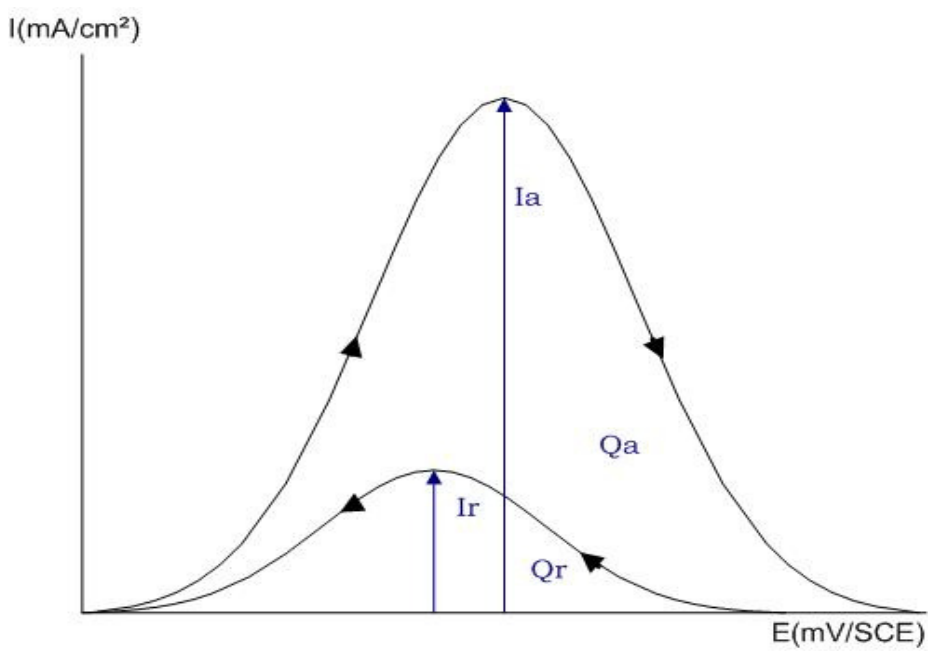

Fig. 1. Principle of DL-ERP on Degree of Sensitization (DOS).

Although the EPR test is well established for austenitic stainless steels and has been used for DSS (2225 ) the test parameters are dependent on surface preparation and material quality.

Samples for DL-ERP tests were cut from areas as close as possible to where macro sections were taken from for metallographic examinations and hardness measurements. Specimens were cut along the 
centerline of the welds to accommodate for an exposed area of $1 \mathrm{~cm}^{2}$ required for the DL-ERP testes and to reveal the relevant weld layers (Root, Fill and Cap).

\section{RESULTS AND DISCUSSION}

The microstructure, resulting phase transformation, mechanical properties and degree of susceptibility to IGC are discussed in detail in this section. Microstructural characterization was performed using optical metallography, macrohardness and energy dispersive X-ray spectroscopy (EDS). Table 3 summarises the results of the mechanical properties of the welded duplex stainless steels carried out in this study, while Fig. 2 shows optical micrographs of the welded regions according to the various welding conditions, as indicated in Table 3.

Table 3 Summary of the results of the mechanical properties of the welded duplex stainless steels.

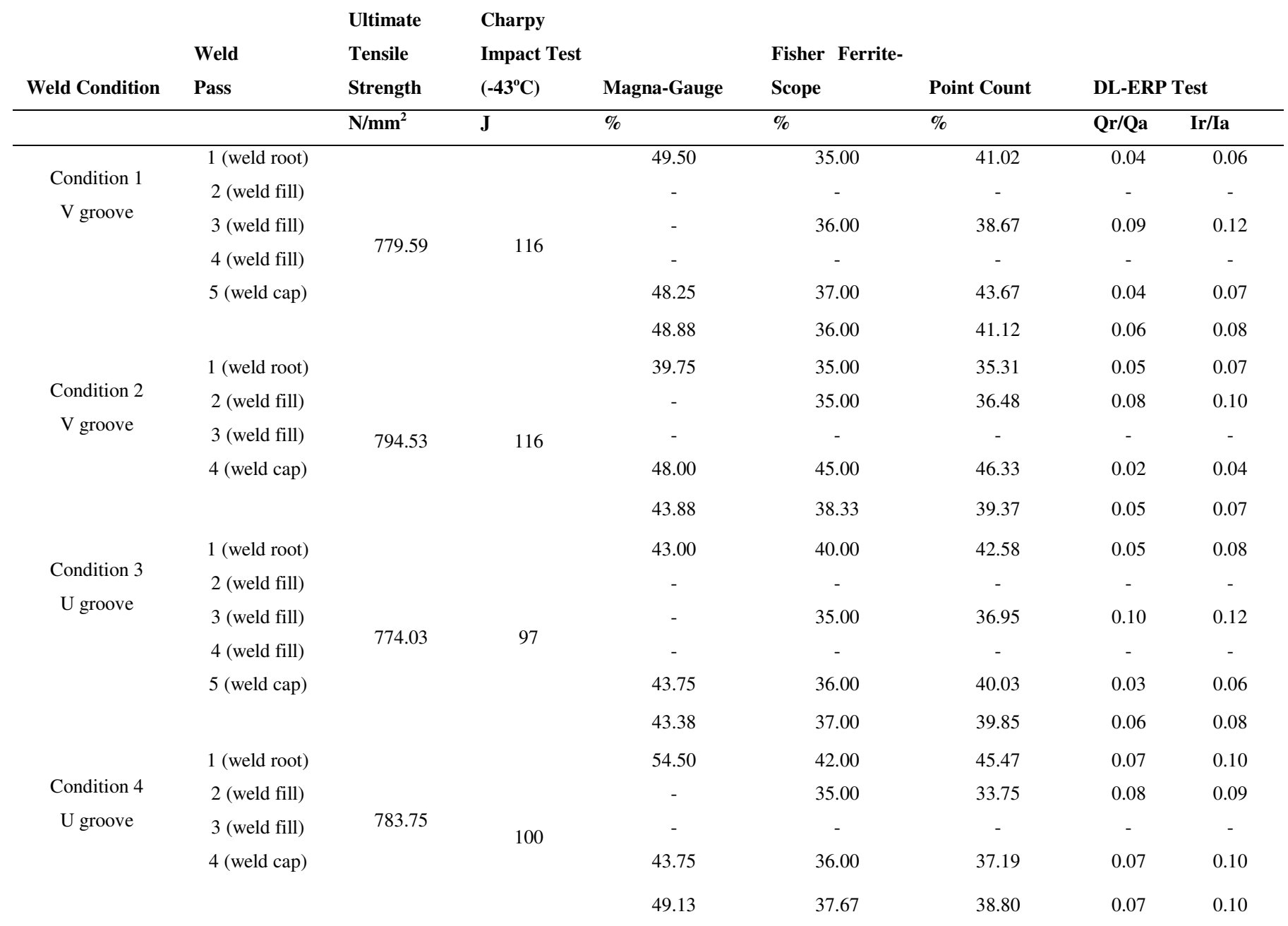



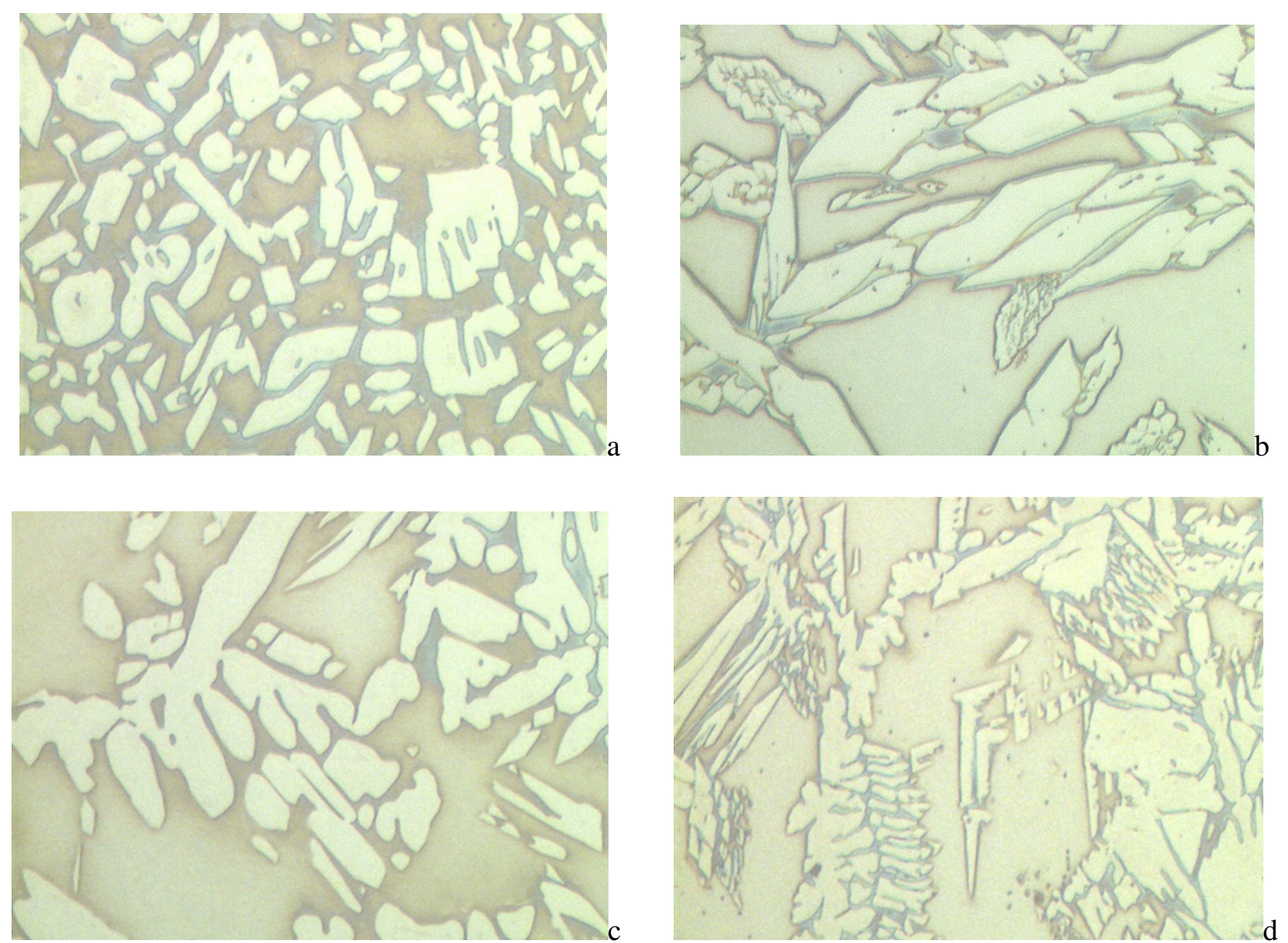

Fig. 2. Optical micrographs of the duplex stainless steels at various weld conditions; a) Root region associated with weld condition 1, b) Fill region associated with weld condition 2, c) Fill region associated with weld condition 3, d) Cap region associated with weld condition 4 (X1000 magnification). 


\subsection{Microstructural Evaluation}

Microstructural analysis for all four GTAW weld conditions as shown by the optical micrographs in Fig 2 reveals the presence of a two-phase banded structure, typical of such materials. In general, the austenite regions observed in the DSS weld metal is formed from ferrite in three modes, viz., as allotriomorphs at the prior-ferrite grain boundaries, as Widmanstätten side-plates growing into the grains from these allotriomorphs and as intragranular precipitates. In the micrographs, the grain boundary allotriomorphs and Widmanstätten austenite are clearly seen. However, the austenite seen within the grain could be either intragranular precipitates or Widmanstätten austenite intercepted transverse to long axis. Fig. 2a shows that the grain boundary austenite layer is not continuous. It is further known that the formation of grain boundary and side-plate fractions requires a relatively smaller driving force (22) and therefore can occur at higher temperatures with little undercooling. The formation of intragranular acicular ferrite, on the other hand, requires a greater degree of undercooling and therefore occurs at lower transformation temperatures. It is likely that a similar transformation sequence is adopted during the microstructural evolution of the regions associated with the DSS weld. Thus the grain boundary austenite and Widmanstätten side-plates form early at higher temperatures, while the intragranular austenite particles require a greater driving force and precipitate later at a lower temperature. This can also be seen in Fig. 2d where the intragranular precipitates are seen to form in the regions partitioned by the Widmanstätten plates. When cooling occurs rapidly in the cap region of the welds, it is expected that the transformation product requiring a higher degree of undercooling is formed.

\subsection{Mechanical Properties}

A graphical representation of the Vickers hardness measurements (10 kg load) on the various welds, taken transversally over the weld regions, as depicted below each graph, are given in; Fig. 3a) for condition 1 and 2 and Fig. 3b) for condition 3 and 4. In the as-welded condition, all the four fusion zones exhibit hardness values in the range of $235-285 \mathrm{HV}_{10}$. The average value in the root run for Condition 1 was $274 \mathrm{HV}_{10}$, with a maximum value of $279 \mathrm{HV}_{10}$. The results taken from condition 4 generally showed values higher than $274 \mathrm{HV}_{10}$. Typical values for the different weld regions were: for the root $\left(281-287 \mathrm{HV}_{10}\right)$, for the fill $\left(274-276 \mathrm{HV}_{10}\right)$ and for the cap $\left(262-276 \mathrm{HV}_{10}\right)$, with the following average values of root $\left(280 \mathrm{HV}_{10}\right)$, fill $\left(273 \mathrm{HV}_{10}\right)$ and cap $\left(268 \mathrm{HV}_{10}\right)$. As for Condition 2 and 3 all weld passes had values lower than $247 \mathrm{HV}_{10}$.

The findings here are significant because there is little difference in the ferrite-austenite proportion in these fusion zones (Root, Fill and Cap). It has been reported that the ferrite and austenite phases do not differ much in composition because substitution elements do not have time to partition significantly during DSS welding (23). However, this was found not to be the case in all Weld Conditions. A comparison of the hardness values and varying amounts of ferrite in the welds show a correlation to the hardness level except for condition 4 where the reverse was observed as shown in Fig.4. 


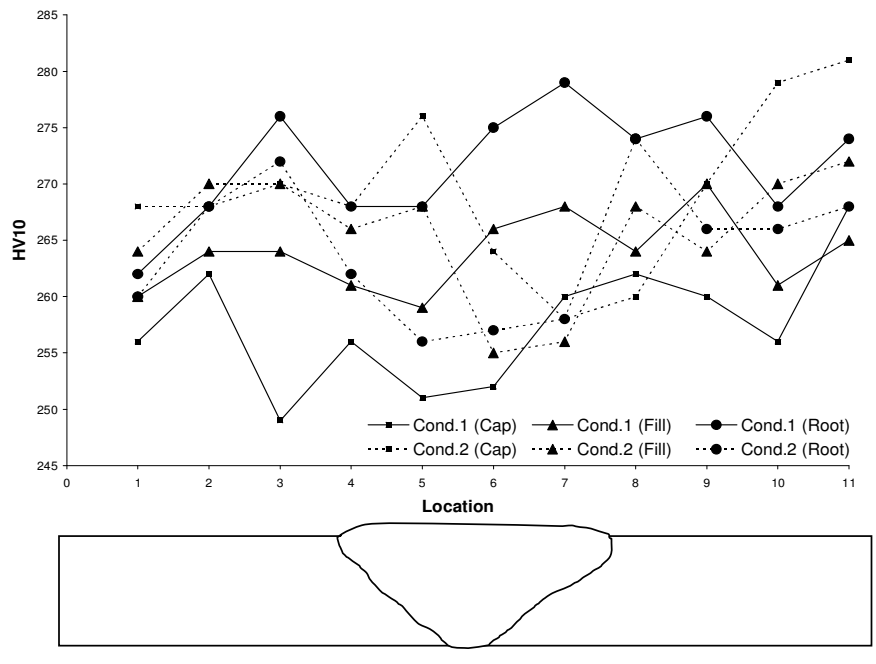

Fig. 3 a) - Hardness profile for Condition 1 and Condition 2
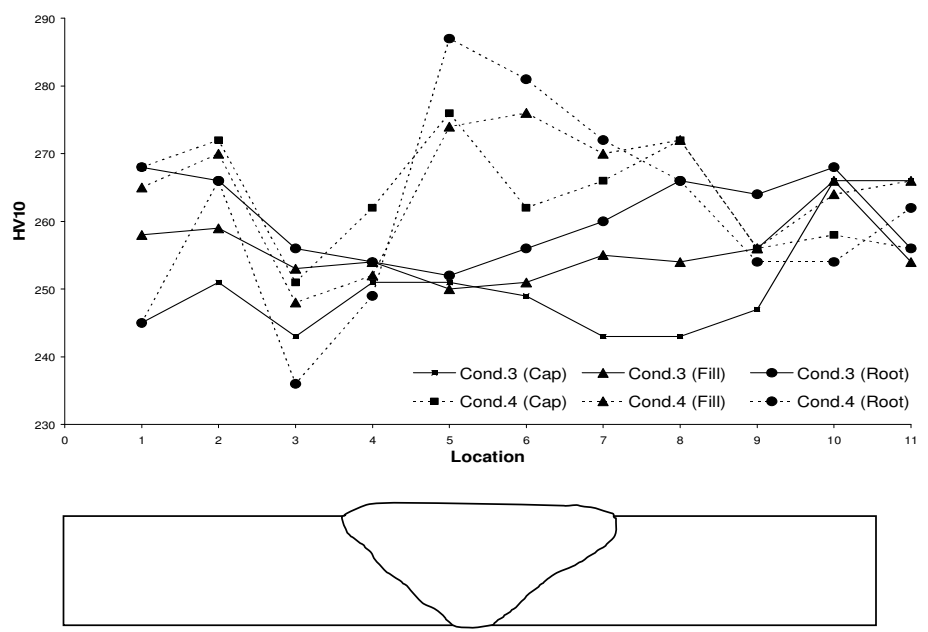

Fig. 3b) - Hardness profile for Condition 3 and Condition 4

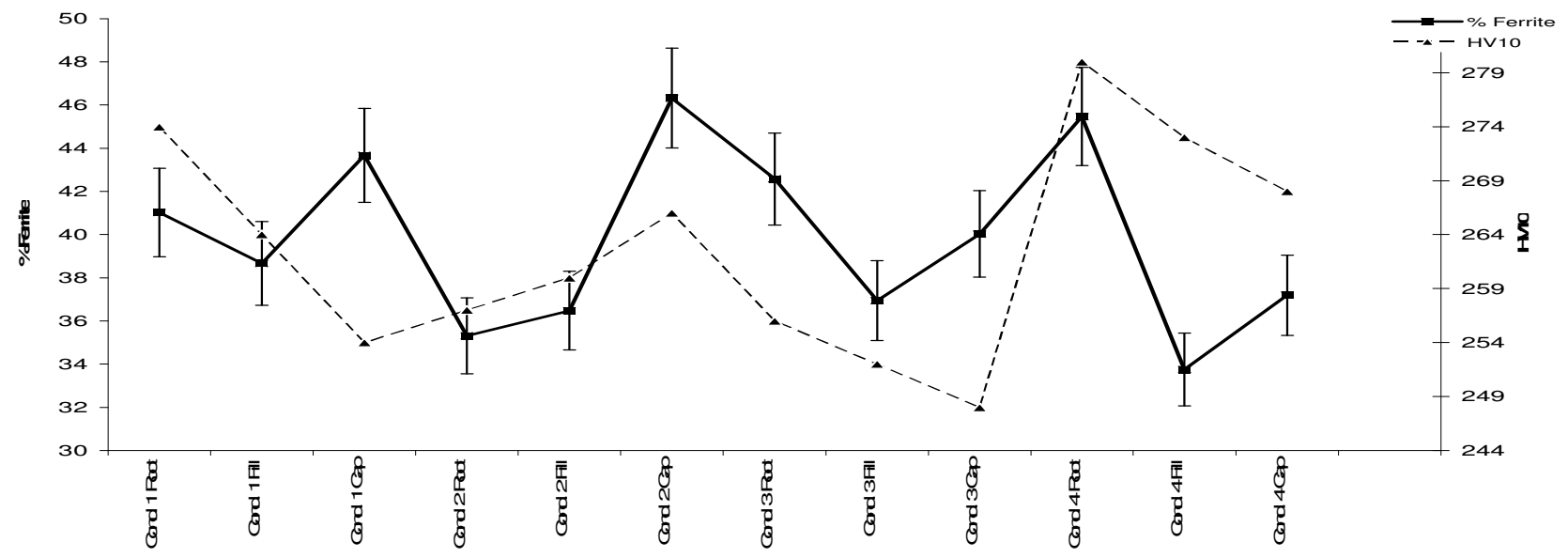

Fig. 4. Correlation of Hardness values and \% ferrite in all conditions.

The notch toughness values obtained by Charpy impact testing at $-43{ }^{\circ} \mathrm{C}$ are listed in Table 3 . The values show that, although slight differences exist in the ferrite content among the four test conditions, condition 1 and 2 had impact values of 116 joules while condition 3 and 4 have impact energy values of 97 joules and 100 joules, indicating a reduction of $16.4 \%$ and $13.8 \%$ respectively. This suggests that the differences in the toughness cannot be explained simply in terms of the changes in ferrite content. The fact that all four weld conditions retain much of their toughness even at $-43^{\circ} \mathrm{C}$ may not be due to a reduction in ferrite-austenite ratio alone. Tensile values for all 4 conditions were within the range of $774 \mathrm{~N} / \mathrm{mm}^{2}$ to $794 \mathrm{~N} / \mathrm{mm}^{2}$. 


\subsection{Intergranular Corrosion Tests}

The results for the modified A262 Standard Practice E test for all conditions were found to be acceptable, with no intermetallic phases observed during metallographic examination. Such findings can also be substantiated by the high impact energy values obtained (97-116 joules). No evidence of sensitization could be observed in all four weld conditions even under a restricted and reduced bending radius as shown in Fig.5.
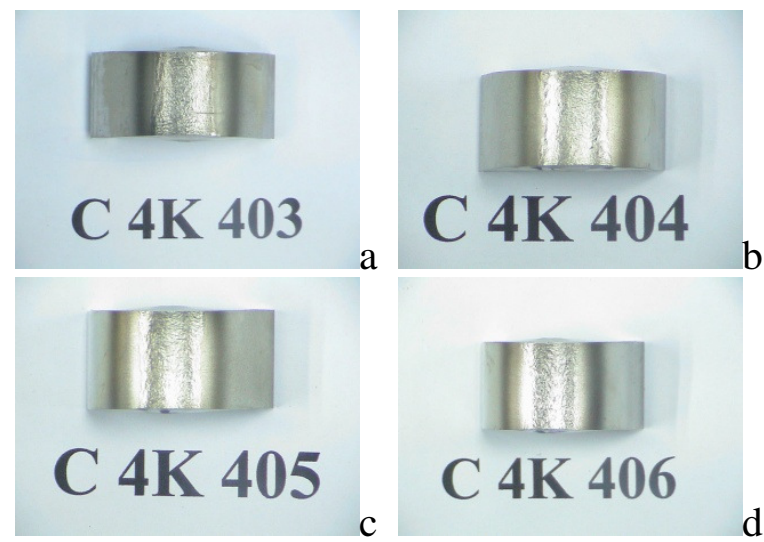

Fig. 5. ASTM A262 Standard Practices E test results, a) Condition 1, b) Condition 2, c) Condition 3, d) Condition 4.

\subsection{Modified DL-ERP test}

The sensitivity of the DSS welds was evaluated using the DL-EPR test, which consisted of subjecting the weld regions to potentiokinetic scanning in a solution of $0.5 \mathrm{M} \mathrm{H}_{2} \mathrm{SO}_{4}+0.001 \mathrm{M}$ TA (thioacetamide), from an active to a passive domain (activation scan), followed by a return to the initial potential (reactivation scan). The test efficiency was measured by means of a response test, which was characterized by weak values of the current density ratio (Ir/Ia $<1 \%$ ) and the charge ratio (Qr/Qa $<1 \%$ ) for nonsensitized materials, and relatively high ratio values ( $\mathrm{Ir} / \mathrm{Ia} \geq 1 \%)$ and ( $\mathrm{Qr} / \mathrm{Qa} \geq 1 \%)$ for highsensitized materials. The reverse polarization from the passive to the active region gave rise to a reactivation peak, the magnitude of which is sensitive to the degree of alloy element depletion. The susceptibility to corrosion was characterized in terms of both the ratio of the reactivation-current peak to the activation current peak as well as the ratio of the reactivation charge to the activation charge (24). Both Ir/Ia and Qr/Qa results are represented graphically in Fig. 6. Analysis of the results shows that the fill region for all four weld conditions had a higher degree of sensitization (DOS) compared to the root and cap region of the welds. It was also observed that collectively, condition 4 had the highest DOS for the root and cap region. 


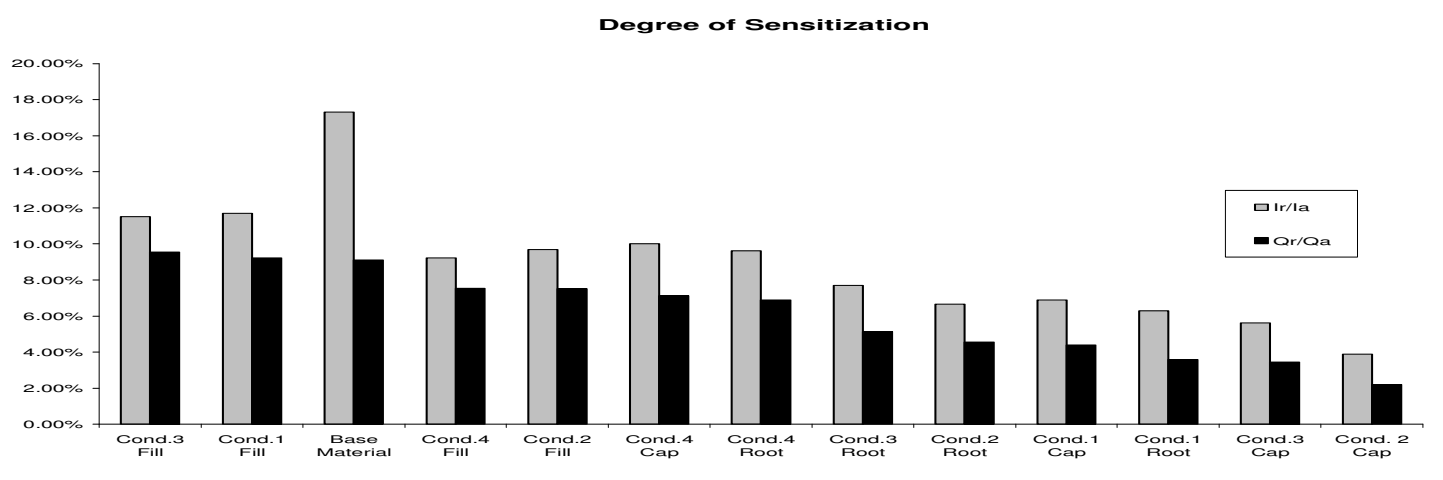

Fig. 6. Results of DL-ERP test showing DOS for all conditions in terms of Qr/Qa and Ir/Ia.

The Ir/Ia and Qr/Qa results were then compared to the percent of Ferrite transformed in each layer (Root, Fill and Cap). A trend was observed where the peaks in the graph were indicative of the highest levels of ferrite in the various conditions correlating to troughs on the Ir/Ia and Qr/Qa lines, and peaks in the Ir/Ia and Qr/Qa lines (Fig. 7).

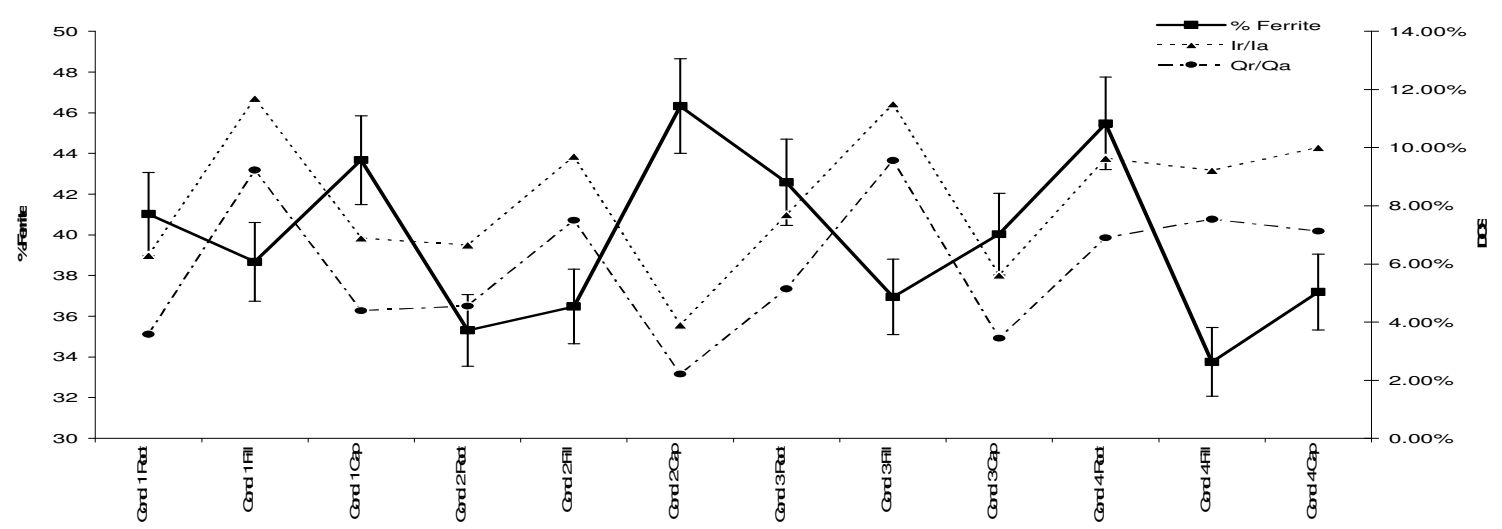

Fig. 7. Correlation of Qr/Qa, Ir/Ia, DOS and \%ferrite in all Conditions.

The results of this study confirm the usefulness of the DL-EPR method in evaluating quantitatively the sensitization of DSS in accordance with previous studies (19-21). The DL-EPR method has the advantage of being a fast and quantitative test that can easily be incorporated into the monitoring of equipment to identify IGC in particular (24).

\subsection{Structural Analysis of Corroded Weld Regions}

EDS Analysis was performed on the cap region of condition 1 and all weld locations of condition 4, to determine the distribution of elements present in the austenite and ferrite phases and to provide confirmation of the mechanisms by which phase transformation were occurring. The various DL-ERP test results are shown in Fig 8,10 and 11. Little information is available in the literature regarding the 
width and depth of depleted zones. Since precipitates were not observed, therefore this could not be determined. Never the less a clear indication of elements, e.g. $\mathrm{Cr}$ and $\mathrm{Ni}$, preferentially nucleating in the ferrite and austenite regions in relative $\%$ is evident in the results obtained (Fig. 11). A correlation therefore seems to exist between precipitate size and corrosion resistance. This view is supported by results from a comparative study showing that smaller precipitates formed by welding were less detrimental than larger produced by isothermal aging $(1-7,22,23)$.

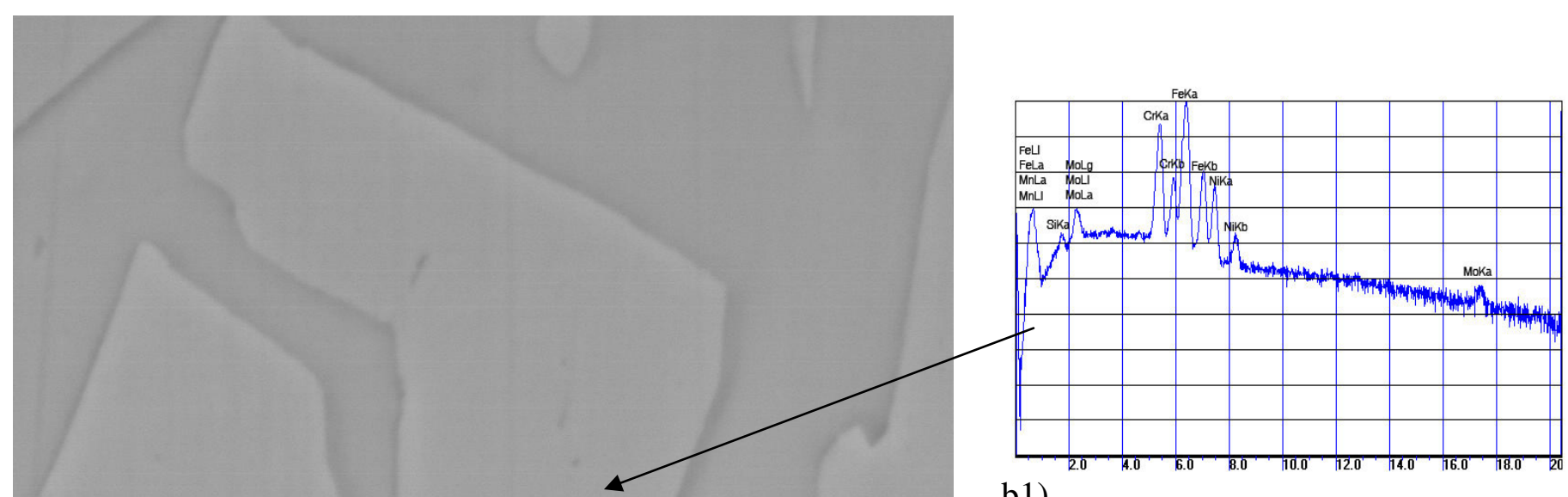

b1)

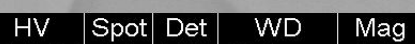
$20.0 \mathrm{kV} 5.0$ ETD $10.0 \mathrm{~mm} 5000 \mathrm{x}$

a)

c)

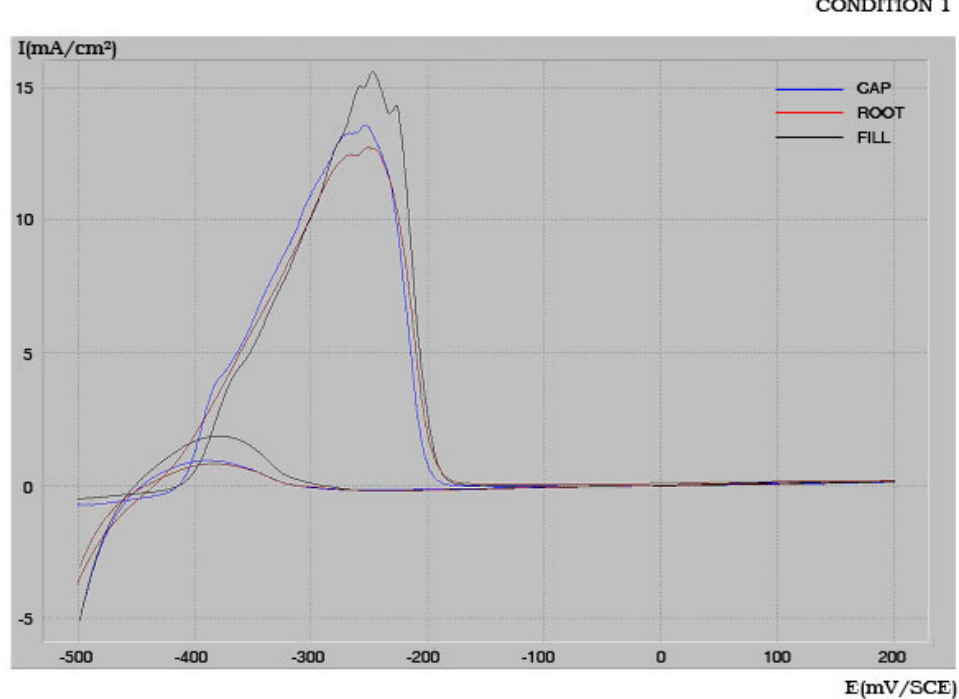

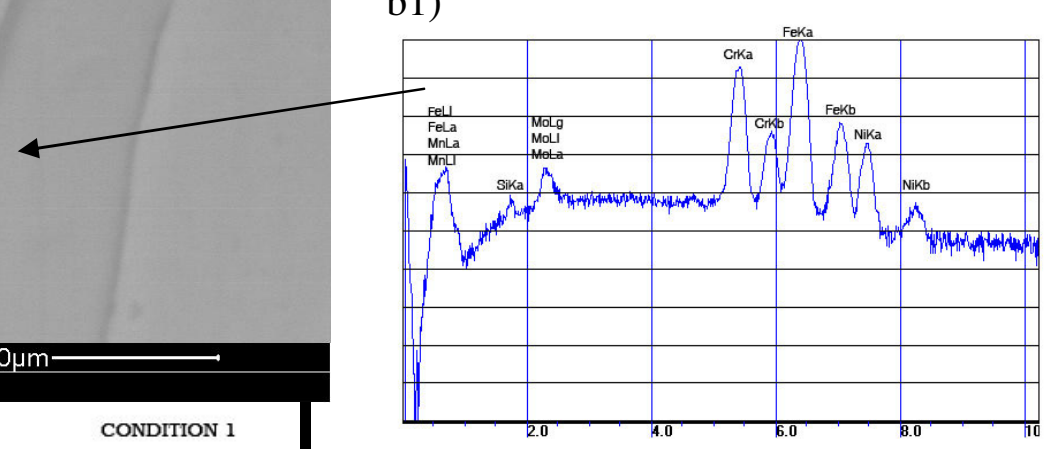

b2)

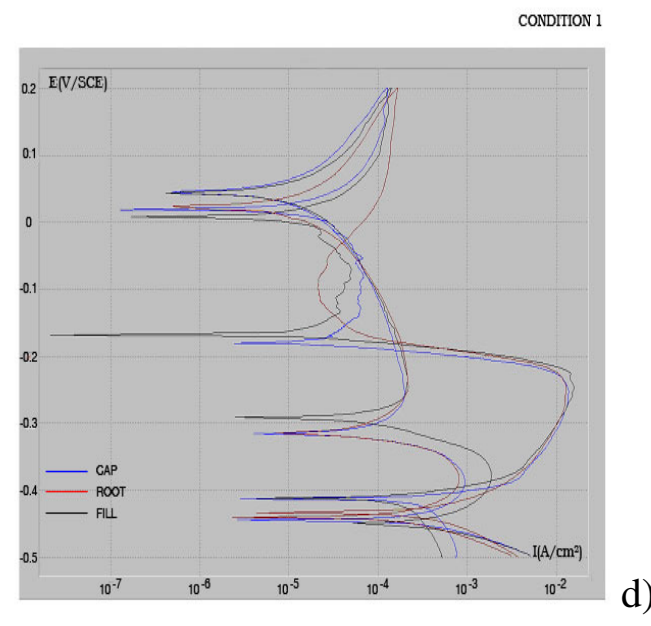

Fig. 8. a) SEM image of Cap in Condition 1 etched with $15 \% \mathrm{NaOH}$, b1) EDS analysis of Austenite in Cap region of Condition 1, b2) EDS analysis of Ferrite in Cap region of Condition 1, c) DL-ERP plot of Root, Fill and Cap region in Condition 1 showing difference in DOS in $0.5 \mathrm{M} \mathrm{H}_{2} \mathrm{SO}_{4}+0.001 \mathrm{M}$ TA, d) Anodic Polarization curve of Root, Fill and Cap region in Condition 1, 0.5 $\mathrm{M} \mathrm{H}_{2} \mathrm{SO}_{4}+0.001 \mathrm{M}$ TA. 
CONDITION 2

CONDITION 3
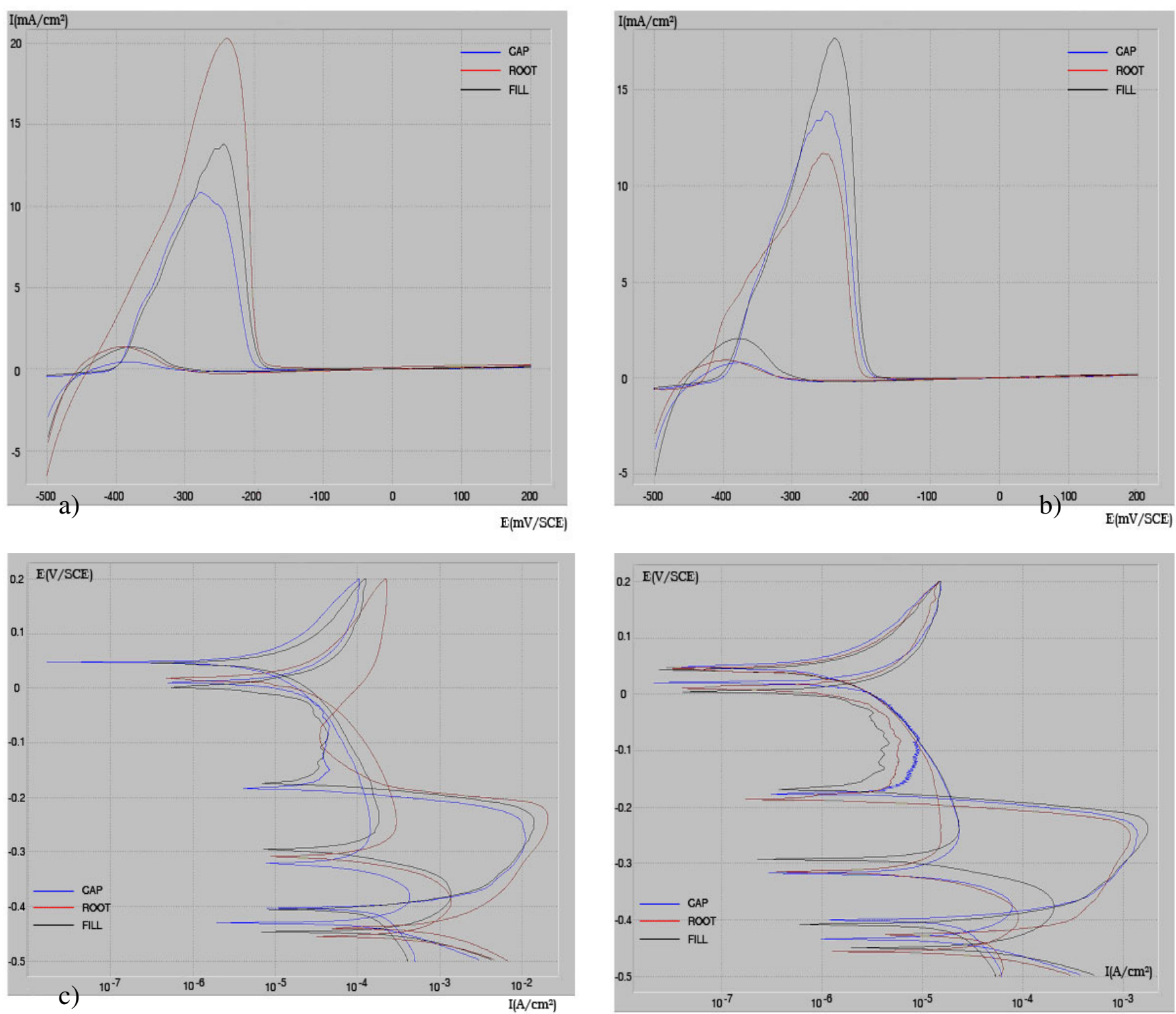

d)

Fig. 9. a) DL-ERP plot of Root, Fill and Cap region in Condition 2 showing difference in DOS in $0.5 \mathrm{M}$ $\mathrm{H}_{2} \mathrm{SO}_{4}+0.001 \mathrm{M}$ TA, b) Anodic Polarization curve of Root, Fill and Cap region in Condition 2, 0.5M $\mathrm{H}_{2} \mathrm{SO}_{4}+0.001 \mathrm{M}$ TA. c) DL-ERP plot of Root, Fill and Cap region in Condition 3 showing difference in DOS in $0.5 \mathrm{M} \mathrm{H}_{2} \mathrm{SO}_{4}+0.001 \mathrm{M}$ TA, d) Anodic Polarization curve of Root, Fill and Cap region in Condition 3, 0.5 $\mathrm{M} \mathrm{H}_{2} \mathrm{SO}_{4}+0.001 \mathrm{M}$ TA. 

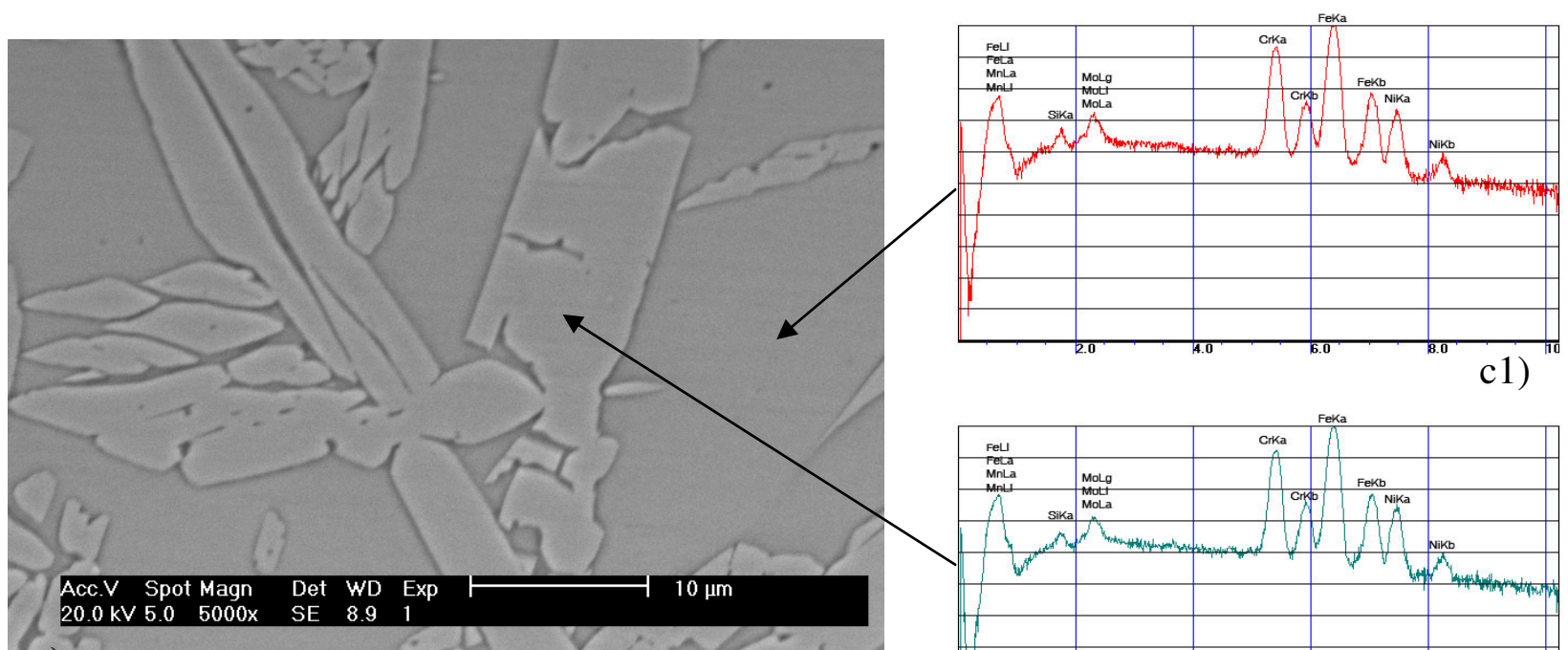

a)

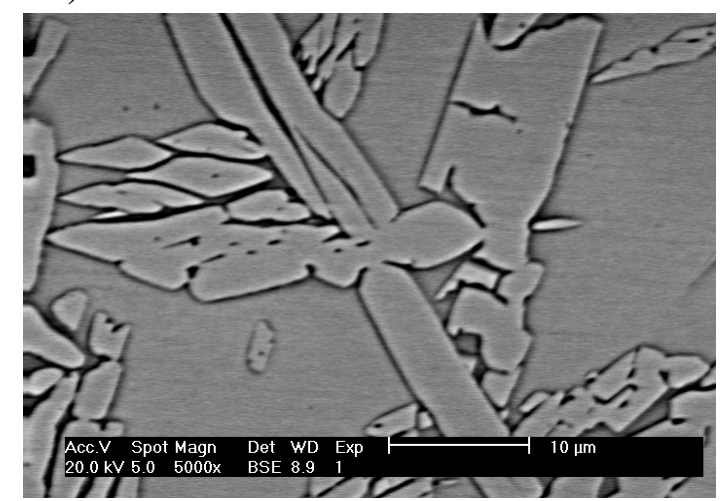

b)

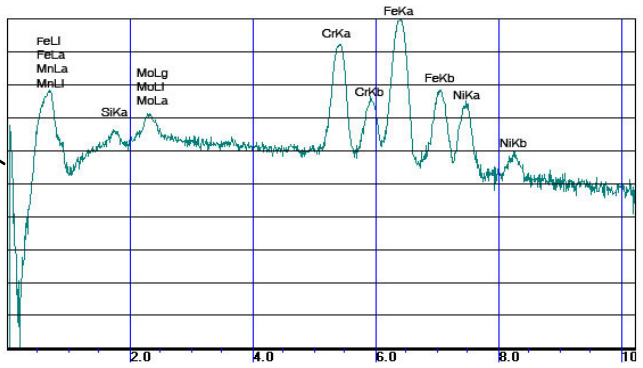

c2)

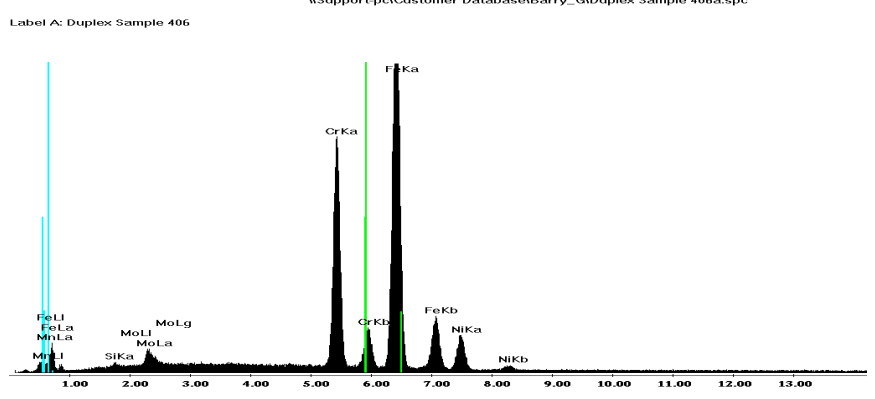

d)

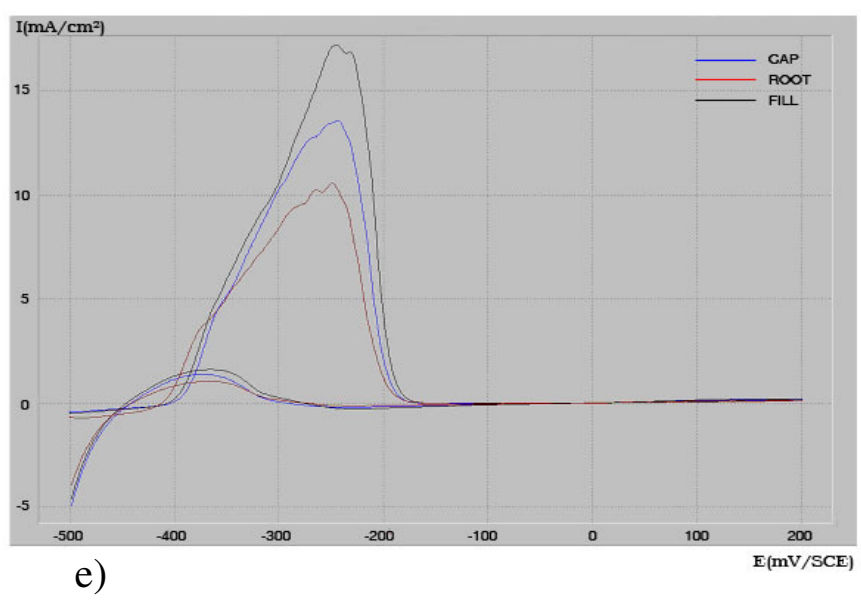

CONDITION 4

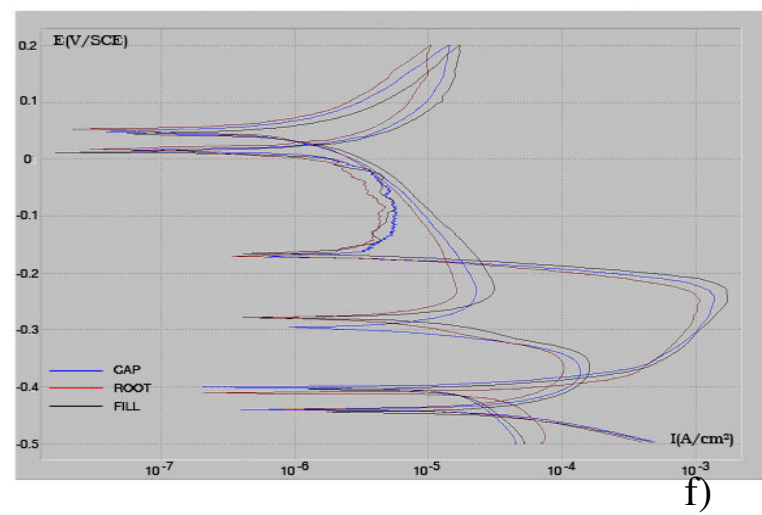

Fig. 10. a) Secondary electron ( SE) image, showing surface features of Fill region of Condition 4 etched with $15 \% \mathrm{NaOH}$, b) Back-Scattered Electron (BSE) yielding images where different phases of differing mean atomic number stand out sharply in the Fill region of Condition 4 etched with $15 \% \mathrm{NaOH} \mathrm{c1)}$ EDS analysis of Ferrite in Fill region of Condition 4, c2) EDS analysis of Austenite region in Fill region of Condition 4, d) EDS analysis entire Fill region of Condition 4, , e) DL-ERP plot of Root, Fill and Cap region in Condition 4 showing difference in DOS in $0.5 \mathrm{M} \mathrm{H}_{2} \mathrm{SO}_{4}+0.001 \mathrm{M} \mathrm{TA}, \mathrm{f}$ ) Anodic Polarization curve of Root, Fill and Cap region in Condition 4, 0.5 $\mathrm{M} \mathrm{H}_{2} \mathrm{SO}_{4}+0.001 \mathrm{M}$ TA. 


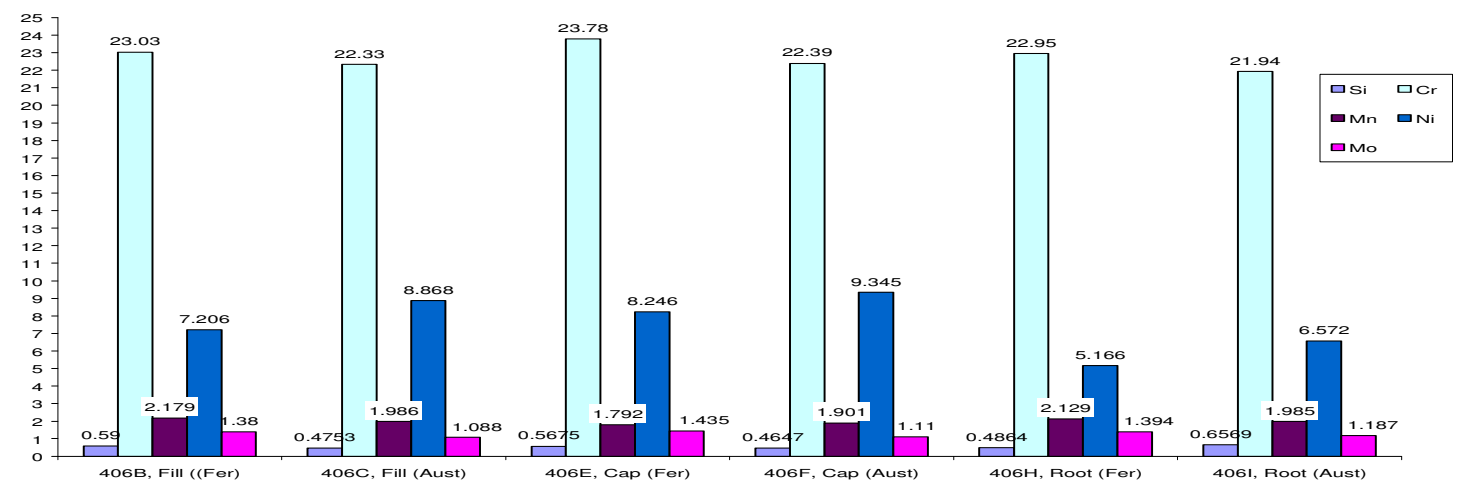

Fig. 11. EDS results on relative distribution of elements in austenite and ferrite regions of the root, fill and cap regions associated with Condition 4.

\section{CONCLUSION}

As a consequence of the varying heat inputs from $1.5 \mathrm{~kJ}$ to $2.0 \mathrm{~kJ}$, for the 4 different weld conditions, there was a move towards the development of a structure containing 35-47\% ferrite. Analysis of data given in Tables 2, suggests that control of heat input was not a significant factor in influencing the specific weld metal mechanical properties within the conditions specified. It was established that there was no relationship between the percentage ferrite content in the notch region and the toughness although results of impact testing differ by approximately $16 \%$ for Condition 3 and $14 \%$ for Condition 4.

The optical microstructure of the weld metal as detailed in Fig. 1 shows a formation of a finer and coarse structure within the weld metal dependent on the level of undercooling which would be expected in a welding process, since the weld metal in the cap region would cool down more quickly as a result of the lower ambient temperature of the weld surface and adjacent parent material at the start of welding. There was no evidence of secondary austenite $\left(\gamma^{\prime}\right)$, being present in any of the weld metal conditions examined. In addition, no areas were observed to contain any of the normally expected intermetallic phases or carbides, even at higher magnifications (X 80000 times) used in the present study.

The resultant hardness values in Condition 1 and 3 exhibited higher hardness values. There was a significant correlation between the hardness values and the $\%$ transformation of Ferrite in all conditions except for Condition 4 where the reverse was observed in the root, fill and cap region as shown in Fig. 4.

All 4 test conditions passed the qualitative type IGC tests even under restricted and modified conditions. 
The DL-ERP test results revealed that the fill area for all 4 test conditions and the base material had the highest values for Ir/Ia and Qr/Qa. It was also determined that Condition 4 had the highest DOS based on DL-ERP test conducted even though Condition 4 had the lowest average heat input.

EDS was used for qualitative elemental analysis to determine which elements were present and their relative abundance. In general, depletion was expected to be the most pronounced in ferrite since (i) intermetallic particles mainly grow into the ferrite regions and (ii) diffusion is faster in ferrite than in austenite (6-9).

\section{REFERENCE}

1. V. Muthupandi, P. Bala Srinavasan, S.K. Seshadri and S. Sunderasen; Materials Science and Engineering A, Volume 358, issue 1-2, 15 October 2003.

2. B.D. Craig, Sour Gas Design Consideration, SPE Monograph No. 15, 1993.

3. M. Liljas, Proceedings of the Fourth International Conference on Duplex Stainless Steels, Glasgow, Scotland, Keynote Paper V, vol. 2, 13-16 Nov 1994.

4. A.J. Ramiraz, J.C. Lippold and S.D. Brandi, Metallurgical and Materials Transaction A, Vol. 34A, Aug 2003, pg. 1575-1597.

5. N. Stephenson, Welding and Metal Fabrication, 55, 5 and 6, 1987, 159-164.

6. R.N. Gun, Editor, Duplex Stainless Steels,: Microstructure, Properties and Applications, Abington Publishing, Cambridge, England, 1997.

7. L. KARLSSON, L. RYEN, and S. PAK: Weld J, $1995_{9} 74,28 \mathrm{~s}-40 \mathrm{~s}$.

8. J.O. NILSSON and P. Lru: Mater. Sci. Technol., 1991, 79 (9), 853 - 862.

9. A. RADJARVIIA, G. METuR, and M. GANTOIS: Proc. Conf. Duplex Stainless Steels '91, Beaune, France, October 1991, Societe Frangaise de Metallurgie et de Mat6riaux, 119-126.

10. L. KARLSSON: Proc. Conf. Duplex Stainless Steels '97, Maastricht, The Netherlands, October 1997; Stainl. Steel World, 1997, 43-58.

11. J.-O. NILSSON, L. KARLSSON, and J.-O. ANDERSSON: Mater. SCL. Technol., 1995, 119 (3), 276-283.

12. S. JANA: 'Innovation stainless steel', 3343-3348; 1993, Florence, Associazione Italiana di Metallurgia.

13. S. ATAMERT and J. E. KING: ACta. Metall, 1991, 399 273-285.

14. H. J. Yu: Proc 4th Int. Conf. on Trends in Welding Research, 87-92; 1995, Materials Park, OH, ASM International.

15. N.A. Mc Pherson, Y. Li and T.N. Baker, Science and Technology of Welding Journal, 2000,, Vol. 5, No. 4, pg 235-244.

16. ASTM E562, Standard Test Method for Determining Volume Fraction by Systematic Manual Point Count

17. ASTM A370, Standard Test Methods and Definitions for Mechanical Testing of Steel Products

18. ASTM G108, Standard Test Method for Electrochemical Reactivation (EPR) for Detecting Sensitization of AISI Type 304 and 304L Stainless Steels 
19. S. Schultze, J. Gollner, K. Eick, P. Veit, I. Garz, “ The modified EPR test: A new tool for examination of corrosion susceptibility of duplex stainless steel”, Duplex '97, Paper D97-067, KCI Publishing, Zutphen, The Netherlands (1997), p 639.

20. A. Turnbull, P.E. Francis, A.J. Griffiths, E. Bennett, W. Nimmo, "Measurement of Corrosion Resistance of Super-Duplex Stainless Steel Welds by Electrochemical Techniques," Eurocorr” 2000 (London, U.K.: Institute of Materials, 2000).

21. E. Otero, C. Merino, C. Fosca, P. Fernandez, "Electrochemical Characterization of Secondary Phases in a Duplex Stainless Steel by EPR Test," Duplex '94, paper no. 56 (Cambridge, U.K.: TWI, 1994).

22. B.J. Ginn and T.G. Gooch: 'Effect of Intermetallic Content on Pitting Resistance of FerriticAustenitic Stainless Steels', proc. conf. Stainless Steels'91 Science and market, Chia Laguna Sardinia, Italy, 1999, vol. 3, p. 81-89.

23. L. Karlsson: 'Intermetallic Phase Precipitation in Duplex Stainless Steels and Weld Metals: Metallurgy, Influence on Properties and Testing Aspects', Welding in the World, vol. 43, no. 5, 1999.

24. T. Amadou, C. Braham, and H. Sidhom; Metallurgical and Materials Transactions A Vol. 35A, Nov. 2004-3499

25. ASTM A262, Standard Practices for Detecting Susceptibility to Intergranular Attack in Austenitic Stainless Steels

26. Verneau, M., Lojewski, C. and Charles, J., “ Modified EPR test for duplex stainless steels surface contamination and microstructural investigation, Duplex '91, Les Editions de Physique, 1991, pp 863-870.

27. Merino, P., Novoa, X.R., Pena, G., Porto, E. and Espada, L., "Study of the intergranular corrosion susceptibility of duplex stainless steels using potentiokinetic reactivation tests (PRT), Duplex '91, Les Editions de Physique, 1991, pp 871-875.

28. Scully, J. R. and Kelly, R.G., Corrosion, 42 (1986), 537-542.

29. Otero, E., Merino, C. Fosca, C. and Fernadez, P., "Electrochemical characterisation of secondary phases in a duplex stainless steel by EPR test”, Duplex '94, TWI, 1994, Paper 56. 